\title{
Confrontación y consenso: la concertación social y el juego de intereses en España (1977-2010)
}

\author{
Ángeles González
}

La concertación social pareció cobrar un renovado impulso en la primavera de 2008 cuando, en plena campaña electoral y ante un contexto económico entonces solo preocupante, el líder socialista José Luis Rodríguez Zapatero propuso «un nuevo compromiso de diálogo social». El ofrecimiento recibió una rápida y favorable acogida. El retorno de la política de pactos sociales pasó a ser, desde ese mismo momento, una demanda compartida por amplios sectores económicos, políticos y mediáticos. No faltaron incluso los que reclamaron una reedición de los Pactos de la Moncloa, considerado el hito fundacional de la concertación, para solventar los graves desequilibrios de la economía española ${ }^{1}$.

La invitación de Rodríguez Zapatero se materializó en una «Declaración para el diálogo social», firmada por el ejecutivo y los interlocutores sociales, que podría considerarse como el primer paso para reactivar la concertación. Esto es, un acuerdo trilateral en el que se produce un complejo intercambio de recursos de naturaleza política entre las partes. De un lado, el Gobierno acepta someter sus decisiones al proceso de diálogo y negociación y, a cambio, suele obtener un reforzamiento de su poder de dirección política. De otro, los agentes sociales reciben una serie de recursos que permiten un cierto equilibrio entre los intereses

1 La oferta fue aceptada por la CEOE, que solicitó del Gobierno un «gran pacto de consenso» con los agentes sociales «para que la economía española salga de la crisis actual», El País, 9-4 y 25-5-2008. Los sindicatos se mostraron favorables siempre y cuando se limitara a negociar el cambio de modelo productivo, La Vanguardia, 2-5-2008. La reedición de los Pactos de la Moncloa fue propuesta por Pedro J. Ramírez, El Mundo, 14-7-2008 y por Durán i Lleida, portavoz parlamentario de CiU, El País, 28-7-2008. El Círculo de Economía solicitó la inclusión en el futuro pacto de los líderes de los principales grupos políticos y gobiernos autonómicos. El ex presidente Felipe González coincidía con el PP en la necesidad de un consenso de Estado ante la crisis, El País, 25-3, 1 y 24-7-2008. 
que representan y disciplinan y, en contrapartida, se convierten en cogestores de las políticas públicas y, como tales, en actores del sistema político².

De vuelta a la declaración, conviene que nos detengamos en algunos aspectos. La ausencia de los partidos políticos es uno de ellos. Pese a los requerimientos para una renovación, siquiera del espíritu -como matizó Joseph Antoni Durán i Lleida- que hizo posible los Pactos de la Moncloa, Rodríguez Zapatero descartó esa posibilidad. La existencia de ciertos paralelismos con la situación de treinta años atrás -el agotamiento del modelo de crecimiento interno coincidente con una crisis de ámbito internacional y un Gobierno sin mayoría absoluta- no puede ocultar una diferencia sustancial. No se trata ya de facilitar la construcción y consolidación de un régimen democrático bajo la fórmula del consenso entre los actores políticos en el que participan necesariamente los agentes sociales. La profunda desconfianza entre el partido en el Gobierno y el principal partido de oposición, a la que se unía el radical desacuerdo sobre los medios conducentes para resolver la crisis, imposibilitó, además, la activación de ese espíritu³.

Una segunda apreciación radica en el uso de los términos compromiso y diálogo. Un lenguaje que anuncia la voluntad compartida, o el deseo, de iniciar una negociación para llegar a un acuerdo ${ }^{4}$. Dicho de otro modo, la declaración no pasaba de ser un mensaje de confianza a los agentes sociales y a la opinión pública ante el malestar provocado por la crisis. Aún así, de inmediato salieron a relucir las profundas diferencias entre las partes sobre las estrategias y objetivos a conseguir. Para el Gobierno se trataba de recuperar el crecimiento económico y mantener los niveles de protección social. La CEOE, en la persona de José María Cuevas, sostenía la exigencia de un crecimiento económico más equilibrado y reformas estructurales, entre las que incluía la del mercado laboral. Por lo que se refiere a los sindicatos, el secretario general de CC.OO., José María Fidalgo, reclamó el reforzamiento de los servicios públicos de empleo y el impulso a la formación profesional en tanto que su homólogo ugetista, Cándido Méndez,

2 Existe una amplia bibliografía sobre la cooperación entre las organizaciones de interés y los gobiernos en la implementación de políticas públicas. Véase, por ejemplo, Lembruch, Gerhard, «Liberal Corporatism and Party Government», Comparative Political Studies, vol. 10, 1 (1977), pp. 91-126; Henley, Andrew y Tsakalotos, Euclid, Corporatism and Economic Performance. A comparative Analysis of Market Economies, Aldershot, Elgar, 1993; Gioacchino, Debora di, Ginebri, Sergio y Sabani, Laura, The role of organized interest groups in policy making, New York, Palgrave Macmillan, 2004.

3 El paquete de medidas del PP incluía, entre otros puntos, la reducción de impuestos y del gasto público al 2\%. El presidente del Gobierno rechazó el recorte con el fin de mantener los compromisos contraídos en materia social, El País, 23-7-2008.

4 La distinción entre diálogo y concertación social en Monereo Pérez, José Luis, Concertación y diálogo social, Valladolid, Lex Nova, 1999, pp. 19-20. 
abogó por una subida salarial superior al índice de precios al consumo (IPC) para reactivar la demanda 5 .

Resulta evidente la existencia de visiones distintas, incluso opuestas, sobre cómo debía producirse la salida de la crisis y de qué manera había que avanzar hacia un modelo de crecimiento equilibrado. Las discrepancias, sin embargo, no impidieron la firma del compromiso, percibido como la fórmula idónea para afrontar la situación. En definitiva, la apuesta por la concertación social se ha revitalizado en 2008, al igual que lo fue hace tres décadas, como respuesta a una situación de crisis económica cuya solución precisa la colaboración entre un Gobierno carente de mayoría parlamentaria y los agentes sociales para la elaboración y ejecución de un programa de ajuste y estabilización ${ }^{6}$.

La necesidad de medidas estructurales que precisan para su eficacia de un consenso Gobierno-agentes sociales, sin duda es un buen acicate pero no el único. Entra en juego, además, la estimación que cada uno de los actores ha realizado sobre los costes y beneficios del compromiso asumido. En otras palabras, las expectativas de alcanzar en el proceso de diálogo -en todo o al menos en parte- objetivos específicos, definidos en función de sus propios intereses. Planteamiento éste corroborado por la CEOE que, pese a la prioridad dada al empleo y la exclusión de una reforma del mercado laboral en la declaración, justificó su firma porque «ha pesado nuestro compromiso en el diálogo y evitar un desencuentro que no nos podemos permitir» ${ }^{7}$. En consonancia con ello, la concertación es un proceso en el que la confrontación y el consenso siempre están presentes, condicionados siempre por la coyuntura política y la situación interna de las organizaciones de interés y del propio Gobierno ${ }^{8}$. Desde mediados de los 90 y al igual que sucede en otros países europeos, la práctica concertadora ha venido condicionada, además, por un tercer factor de naturaleza bien distinta. La necesidad de responder a los nuevos requerimientos, derivados de la necesidad de preservar la competitividad y el empleo en una economía globalizada, reactivó los pactos tripartitos como procedimiento idóneo para una «renegociación», vía corporatista, del Estado del Bienestar. En ese proceso las reformas en los mer-

5 El País, 25-5-2008 y El Mundo, 29-7-2008.

6 En realidad, la concertación se puso en práctica en muchos países europeos en fases de crecimiento para distribuir de manera equilibrada los excedentes. Cabe resaltar, por otro lado, que el acuerdo firmado en 2006 sobre el mercado laboral se insertó en una fase de expansión económica.

7 El País, 30-7-2008

8 ReGinI, Marino, «Las condiciones para el intercambio político: ascenso y decadencia de la concertación en Italia y Gran Bretaña», en GoLDTHORPE, John H., Orden y conflicto en el capitalismo contemporáneo, Madrid, MTSS, 1991, p. 188. Oliet PaLÁ, Alberto, Liberalismo y democracia en crisis, Madrid, CES, 1994, pp. 204-206. 
cados laborales aplicadas en algunos países europeos ha supuesto una reducción de los mecanismos de protección del empleo, que en el caso de España se ha hecho extensiva también a los contratos indefinidos 9 .

Los condicionantes internos provocaron un primer fracaso de las negociaciones a finales de julio de 2009. Como es habitual en estos casos, la ruptura fue oportunamente escenificada con un intercambio de reproches y acusaciones mutuas. Gobierno y sindicatos atribuyeron a la CEOE la responsabilidad del fin del diálogo social, en tanto que ésta achacaba al primero la autoría del fiasco ${ }^{10}$. El detonante de la ruptura, la petición de la patronal de una reforma del mercado laboral y la rebaja de las cotizaciones sociales a las empresas, a la que se oponían de manera rotunda sindicatos y Gobierno, no explica por sí solo el abrupto final de las negociaciones. Intervinieron, además, factores de diversa naturaleza. Entre ellos, la crisis de liderazgo en el seno de la CEOE, la baja credibilidad de los sindicatos y la apuesta del Gobierno a favor de éstos últimos. Su negativa a una reducción de los derechos laborales conquistados por los trabajadores echaba al olvido que la concertación en España se ha basado, en buena parte aunque no siempre, en una aminoración pactada de esos derechos para salvar el empleo y en el intercambio de moderación salarial por reconocimiento institucional de los sindicatos ${ }^{11}$. El temor a una nueva huelga general y el presumible coste electoral

9 WaARDEn, Frans van and Lehmbruch, Gerhard, Renegotiating the welfare state: flexible adjustement through corporatist concertation, London, Routledge, 2003; «(The governments) have left the existing provisions for permanent (or regular) contracts practically unaltered (with the exception of Spain) and relaxed only EPL for temporary jobs», en OcheL, Wolfgang, «The political economy of Two-Tier reforms of Employment Protection in Europe», CESIFO Working Paper, n. ${ }^{\circ}$ 2461, www. CESifo-group.org/wp, p. 2.

10 Para Rodríguez Zapatero la de la CEOE, «no es una propuesta para el diálogo, es una propuesta para el final del diálogo». Su actitud respondía, según los sindicatos, a «cálculos políticos», en referencia a un supuesto apoyo al PP, El País, 25-7-2009. «La CEOE no firmará un acuerdo si no se abre un verdadero debate sobre reformas estructurales (...) En las manos del ejecutivo está. Es él quien ha roto el diálogo y nosotros sólo estamos a la espera de saber qué quiere hacer», $A B C$, 26-7-2009. La versión que ofreció Fidalgo -apartado ya de la dirección de CC.OO.- fue sustancialmente diferente: «En mayo de 2008 estábamos tan alarmados por lo que se nos venía encima que los de CC.OO. propusimos un plan de ajuste de caballo con congelación salarial incluida. Luego, cuando nos convocaron a la mesa del diálogo social, estuvimos un mes entero negociando la declaración porque ellos no querían poner en el papel la palabra crisis», El País, 25-72010.

11 La reversibilidad/irreversibilidad de los derechos laborales en SAGARDOY, Juan Antonio, «Sobre el diálogo social», $A B C, 8-8-2009$. Sobre la pérdida de derechos en las reformas laborales posteriores al Estatuto de los Trabajadores (ET), VV. AA. Más y mejor empleo en un nuevo escenario socioeconómico: por una flexibilidad y seguridad laborales efectivas. Informe de la Comisión de Expertos para el diálogo social, Madrid, MTSS, 2005. Para la derrota del movimiento obrero, paralela a la consolidación e institucionalización de los sindica- 
de la crisis vino a ratificar que, aunque representante del interés general, el Gobierno no es un simple mediador entre los interlocutores sociales, no pretende un arbitraje ni un compromiso entre los distintos intereses. Es una parte más, que actúa en función de lógicas e intereses propios y, en consonancia, actor también de la confrontación ${ }^{12}$.

No resulta extraño que, acompañando a las descalificaciones y críticas mutuas, las partes intentaran tender puentes para, pasado un tiempo prudencial, retomar el diálogo. Las negociaciones comenzaron de nuevo a comienzos de 2010, ahora en un clima enrarecido por la agravación de la crisis y la desconfianza sobre la situación económica y financiera del país en los mercados y organismos internacionales, que apremiaban la aplicación de reformas estructurales para solventar el deterioro de las cuentas públicas. Finalmente, la presión exterior sobre el ejecutivo surtió efecto y, ante la falta de acuerdo de los agentes sociales, a mediados de junio aprobó por decreto-ley una reforma del mercado laboral ${ }^{13}$.

Este apunte sobre un presente fallido permite analizar el proceso de concertación como escenario del juego de intereses entre los actores intervinientes que, en no poca medida, han condicionado su desigual trayectoria. A la época dorada, coincidente con el proceso de transición y consolidación democráticas y de crisis económica (1977-1986), sucedió otra de fuerte expansión y de confrontación entre los agentes sociales, especialmente los sindicatos y el Gobierno. El declive de la concertación ${ }^{14}$ tal como la hemos definido se mantuvo hasta 1994, año en que se reanudó la práctica de los pactos sociales, pero ahora con un carácter bilateral y sobre aspectos específicos, generalmente políticas de empleo y, como hemos apuntado, reformas laborales. Cierto es que en 1997 el acuerdo entre los actores sociales sobre reforma del mercado laboral fue asumido por el

tos, Gálvez Biescas, Sergio, «El movimiento obrero en la España del tiempo vivido: "del sujeto político" al nuevo precariado», Cuadernos de Historia Contemporánea, 30 (2008), p. 209.

12 Garofalo, Michael G., «Naturaleza jurídica de la concertación social», en Ojeda Ávilés, Antonio (dir.), La concertación social tras la crisis, Barcelona, Ariel, 1990, p. 62. Referido al período que se inicia en 1986, García Del CAMPo, Esther, «En el corazón del mercado. Sindicatos y empresarios en la democracia española», Política y Sociedad, 20 (1995), p. 92.

13 Un análisis de su contenido, convalidado por el Parlamento, a comienzos de setiembre, en El País, 27-6-2010. Los sindicatos, que para entonces ya habían retirado su confianza al Gobierno, convocaron una huelga general para el 29 de ese mismo mes.

14 Otros autores optaron por el término recesión, Solé, Carlota, «La recesión del neocorporatismo en España», Papers, 33 (1990) pp. 51-63, e incluso defunción, SEGURA, Julio, «Concertación o conflicto», en Julié, Santos (comp.), La desavenencia: partido, sindicatos y huelga general (selección de textos, introducción y epílogo), Madrid, El País-Aguilar, 1990, p. 279.

Pasado y Memoria. Revista de Historia Contemporánea, 9, 2010, pp 101-128 
Gobierno, que lo trasladó a rango de ley, pero habría que esperar hasta el año 2006 para la firma de un nuevo pacto trilateral que puede insertarse, en sentido estricto, dentro de los parámetros que definen la concertación.

\section{De los Pactos de la Moncloa al Acuerdo Nacional de Empleo}

La política de concertación en España tiene su origen en el contexto de la Transición a la democracia. Las dificultades inherentes a todo proceso de cambio político se vieron agravadas, en este caso, por la presencia de una coyuntura internacional recesiva y una crisis económica interna de carácter estructural ${ }^{15}$. Las primeras elecciones democráticas, celebradas en junio de 1977, dieron lugar a un Gobierno carente de mayoría absoluta con una tarea compleja y difícil por delante. La reforma política, una de sus prioridades, debía conjugarse necesariamente con un plan de ajuste económico. Cuestiones que, por su propia naturaleza y en un contexto de cambio político, no podían ser afrontadas en solitario por el Gobierno y requerían del consenso de los partidos políticos y los agentes sociales. Consciente de dicha exigencia, el ejecutivo pretendió asegurarse el apoyo de empresarios y sindicatos pero el paquete de medidas antiinflacionistas no satisfizo, por razones lógicamente diferentes, a los agentes sociales. Tanto unos como otros sostenían la necesidad de políticas expansivas del gasto público para mejorar las expectativas de negocios y sostener la demanda ${ }^{16}$ de modo que las divergencias sobre el contenido y alcance del programa económico condujeron rápidamente a un callejón sin salida. Muy otro fue el resultado de las negociaciones con las formaciones políticas del arco parlamentario que, a finales de octubre, firmaron los Pactos de la Moncloa, un texto de naturaleza socioeconómico y, sobre todo, político. En estos términos, los acuerdos que, en síntesis, contenían los elementos propios de una política de rentas, un paquete de reformas económicas estructurales y una serie de medidas de estabilización, no pueden considerarse en sentido estricto como el inicio de la política de concertación ${ }^{17}$.

15 Cfr., García Delgado, José Luis y Serrano Sanz, José María, «De la primera crisis energética a las elecciones del 77: tiempo de incertidumbre», en GarCía Delgado, José Luis (dir.), Economía española de la transición y la democracia, Madrid, CIS, 1990, pp. 3-21. Espina, Álvaro, Empleo, democracia y relaciones industriales en España, Madrid, MTSS, 1991, p. 53.

16 El Pais, 31-8-1977.

17 Cfr. Trullen i Thomas, Joan, Fundamentos económicos de la transición política española. La política económica de los Acuerdos de la Moncloa, Madrid, Ministerio de Trabajo y SS., 1993, pp.158-221; Fuentes Quintana, Enrique, «De los Pactos de la Moncloa a la Constitución (julio 1977-diciembre 1978)», en García DelGado, José Luis, Economía española de la transición a la democracia, pp. 31-32. El carácter subalterno de los agentes sociales, aunque atribuida básicamente a los sindicatos, ha llevado a calificar el modelo español 
La conformidad, a posteriori y más bien resignada, de los agentes sociales ha de relacionarse con el marco de las oportunidades políticas y el cálculo costesbeneficios para sus respectivas organizaciones. La necesidad de afianzar el protagonismo político del PSOE y PCE tuvo efectos persuasivos evidentes sobre los sindicatos, pero en su asentimiento también influyeron las contrapartidas obtenidas, especialmente las expectativas de potenciación de las centrales sindicales como «instrumento fundamental de negociación» ${ }^{18}$. Los Pactos constituyeron la vía idónea para que los sindicatos, UGT en particular, lograran el aumento de la afiliación, la construcción de una red organizativa de ámbito nacional y el reconocimiento empresarial y del Estado ${ }^{19}$. Por lo que se refiere a la aceptación de los Pactos como parte de un ejercicio de responsabilidad para asegurar el éxito del cambio político, Fishman subraya que, en todo caso, la desmovilización de los trabajadores desde arriba no tuvo un carácter amplio ni duradero como lo probaría el incremento de la conflictividad en 1979. Aun así, la acción sindical se acomodó a los requerimientos de la Transición -tanto como a los derivados de la crisis económica y de la intensa competencia sindical- y las reivindicaciones sostuvieron una intensidad y ritmo menor del deseado por la mayoría de los militantes ${ }^{20}$. Para la CEOE el procedimiento y los objetivos de los Pactos eran incongruentes y contradictorios, pero la frustración de sus dirigentes no llegó al extremo de rechazar su colaboración. Pese a las amargas críticas sobre su contenido, en el ánimo de sus dirigentes influyó más la necesidad de lograr el reconocimiento de su monopolio representativo sobre los intereses empresariales ${ }^{21}$.

de «concertación corporatista subordinada», Alonso, Luis Enrique, «Conflicto laboral y cambio social. Una aproximación al caso español», en Miguélez, Faustino y Prieto, Carlos, Las relaciones laborales en España, Madrid, Siglo XXI, 1991, pp. 403 y ss.; MarTínez Alier, Joan y Roca, Jordi, «Economía política del corporativismo en el estado español», Revista de Investigaciones Sociológicas, 41 (1988), pp. 25-62.

18 Redero SAN RomÁn, M., «Las relaciones laborales en el franquismo y la transición democrática (1958-1978). Acotaciones al caso de la UGT», en Estudios de la Historia de UGT, Salamanca, 1992, p. 165; «Los sindicatos en la democracia: de la movilización a la gestión», Historia y Política, 20 (julio-diciembre 2008), pp. 129-158.

19 Cfr. Pérez Díaz, Víctor, Clase obrera, orden social y conciencia de clases, Madrid, Fundación del Instituto Nacional de Industria, 1980; Aguilar, Salvador y Roca, Jordi, Sindicalismo i canvi social a Espanya, Barcelona, Fundació Jaume Bofill-Fundació Volkswagen, 1991, vol. 1, p. 221. Condicionantes que explican, entre otros factores, el rechazo de los sindicatos minoritarios a cualquier tipo de pacto.

20 Cfr. Maravall, José María, La política de la transición, Madrid, Taurus, 1995, p. 30. La matización en Fishman, Robert M., Organización obrera y retorno a la democracia en Espa$\tilde{n} a$, Madrid, CIS, 1996, p. 296. La competencia intersindical en Oliet PaLÁ, Alberto, «La concertación social en la transición: la génesis de un modelo de intercambio», Espacio, tiempo y forma, serie V. Historia Contemporánea, 13 (2000), pp. 449.

21 Cfr. González Fernández, Ángeles, «Los empresarios en tiempos de cambio. Poder, nego-

Pasado y Memoria. Revista de Historia Contemporánea, 9, 2010, pp 101-128 
Desde esa perspectiva, los Pactos de la Moncloa constituyeron la oportunidad política para que las organizaciones de interés, CEOE y sindicatos mayoritarios, pudieran adquirir y desenvolverse conforme a las lógicas de afiliación y de influencia, esto es, en función de las características y demandas de sus asociados y de sus interlocutores respectivamente ${ }^{22}$. Iniciaron, además, el camino para una política de acuerdos sociales que les proporcionó un estatus privilegiado, una vez que el Gobierno dictó una serie de normas que fijaban el índice de representatividad como condicionante de las posibilidades de acción, gran parte de las vías de financiación y, también, de su estatus ante los poderes públicos ${ }^{23}$. El sistema, arbitrado precisamente para facilitar la concertación ante la proliferación de organizaciones sindicales y el incremento de la conflictividad, les otorgó presencia institucional en tanto que mediadores sociales y facilitó su actuación en el ámbito político. En contrapartida, asumieron el compromiso de garantizar el cumplimiento de las políticas acordadas y, en consecuencia, el no recurso a formas de conflicto colectivo ${ }^{24}$.

No fue, el de la concertación, un camino fácil. Los encuentros y desencuentros fueron habituales y convirtieron los pactos sociales en un proceso torturado y tortuoso, condicionado por la coyuntura económica, las desavenencias entre las partes y siempre por el calendario político. No hubo acuerdo en 1978, el primero negociado directamente a tres bandas, debido a las reticencias de los sindicatos y a las interferencias de los partidos políticos ante la inminente convocatoria de elecciones ${ }^{25}$. La convicción de que un nuevo acuerdo cargaría otra vez «todo el peso sobre los trabajadores» explica el rechazo sindical al excesivo voluntarismo del ejecutivo en sus objetivos antiinflacionistas. Una postura que fue animada por las estrategias políticas del PCE y PSOE. Dicho en otras palabras, la apuesta de CC.OO. a favor de la continuidad de los Pactos de la Moncloa pretendía un mayor protagonismo y una posición de igualdad del PCE respecto

cio y política en la transición a la democracia», Alcores, 4 (2007) pp. 167-186.

22 Schmitter, Philippe C. y Streeck, Wolfgang, The Organization of Business Interests: Studying the Associative Action of Business in Advanced Industrial Societies, Discusión Paper, IIM/ LMP 81-13, Berlín Wissenschaftszentrum.

23 Sanguinetti Raymond, Wilfredo, «Sindicatos y libertad sindical en España: Dos décadas de vigencia constitucional», en García Laso, Agustín y Sanguinetti Raymond, Wilfredo (eds.), Sindicatos y cambios económicos y sociales, Salamanca, Universidad de Salamanca, 2002, pp. 27-29.

24 PARDO, Rafael, «Organizaciones empresariales, sindicatos y relaciones industriales en el cambio de siglo», en Tusell, Javier, Lamo de Espinosa, Emilio y PARdo, Rafael (eds.), Entre dos siglos. Reflexiones sobre la democracia española, Madrid, Alianza, 1996, p. 474.

25 «El calendario político condiciona la actitud de las fuerzas sociales y del propio gobierno», El País, 1-12-1978. Los objetivos de los interlocutores sociales y la posición del ejecutivo en ibidem, 21 y 26-10-1978. 
a las otras dos grandes formaciones. La actitud de UGT era más ambigua. Aunque se decía partidaria de un acuerdo, lo cierto es que no deseaba el pacto. Sus esperanzas, máxime a la vista de los adversos resultados de las elecciones sindicales celebradas a finales de ese mismo año, se cifraban en el triunfo electoral del PSOE que sería, indudablemente, también un triunfo propio ${ }^{26}$.

A las reticencias de los sindicatos se añadió la reserva de los empresarios a la participación del Gobierno en las negociaciones. El temor a que, presionado por el calendario político, el ejecutivo realizase concesiones a las centrales no se tradujo inicialmente en una actitud de rechazo a su propuesta. La oportunidad para desligarse del pacto la brindó la insistencia de CC.OO. en un acuerdo a cuatro bandas, negado de manera rotunda porque consolidaría su posición como sindicato hegemónico y fortalecería al PCE ${ }^{27}$. El ejecutivo, dispuesto a proseguir su política antiinflacionista y, por tanto, de moderación salarial, solventó el impasse por la vía del decreto-ley. Como era previsible, la limitación salarial del 12\% fijada por el ejecutivo de cara a la negociación colectiva de 1979 fue acogida con simpatías por la CEOE y la oposición de los sindicatos, justificada por el deterioro de la capacidad adquisitiva de los trabajadores. Pero no fue ésta la única razón. Probablemente confiados en su capacidad movilizadora y el desgaste que supondría para el Gobierno y los empresarios una escalada en la conflictividad, denunciaron la intromisión del ejecutivo en la libertad de negociación entre los agentes sociales, tal como había sido reconocida en la Constitución, lo que podría entenderse como rechazo a la concertación ${ }^{28}$. Celebrada por primera vez en un marco de libertad por unas organizaciones -tanto sindicales como empresariales- dispuestas a aplicar una estrategia y una planificación global previamente elaboradas, la negociación colectiva se tradujo -dada la disparidad de posicio-

26 En las elecciones sindicales CC.OO. obtuvo una ventaja de 13,8 puntos porcentuales sobre UGT. «(...) Los sindicatos no estábamos por la labor», Testimonio de J. Almunia en Lamelas, Antonio, La transición en Abril, p. 185. Cfr. Zufiaur, José María, «El sindicalismo español en la transición y la crisis», Papeles de Economía Española, 22 (1985), pp. 202-234.

27 Las reservas en Cabrera, Mercedes y Del Rey, Fernando, El poder de los empresarios. Política y economía en la España contemporánea (1875-2000), Madrid, Taurus, 2002, p. 345; González Fernández, Ángeles, «La estrategia del pacto social. La CEOE ante la transición española a la democracia», en Quirosa-ChEyrouze, Rafael (ed.), La sociedad Española en la Transición. Los movimientos sociales en el proceso democratizador, Madrid, Biblioteca Nueva, pp. $193-204$.

28 «(...) Todos los trabajadores españoles acaban de conquistar, al aprobar la Constitución, el derecho a negociar ellos mismos sus condiciones de trabajo y sus salarios, sin tener que aceptar, en ningún caso, intromisiones de alguien que no les representa, por muy vicepresidente del Gobierno que sea», Mundo Obrero, 26-12-1978. 
nes- en un extraordinario incremento de los conflictos ${ }^{29}$.

Conviene tener en cuenta, en este punto, que toda espiral de huelgas tiene un coste elevado para los sindicatos, sobre todo si se produce -como era el casoen un contexto económico recesivo ante el que los trabajadores suelen reaccionar con actitudes de prudencia y moderación. Ese coste, unido a la necesidad de definir su propio espacio social y a la frustración de sus expectativas en el triunfo electoral del PSOE, provocó un giro en la estrategia de la UGT y el inicio de una política sindical claramente diferenciada.

La ruptura se materializó en el inicio de un período de colaboración entre la patronal y el sindicato socialista que siempre contó con el respaldo del Gobierno, el apoyo de la Fundación Frederich Ebert, cuyos seminarios y encuentros coadyuvaron a la creación de un clima de confianza entre ambos, y las reticencias del PSOE. Unas reservas que únicamente se centraban en el posible sostén que esos acuerdos podrían otorgar al Gobierno y en ningún caso hacia la ruptura con Comisiones Obreras ${ }^{30}$. El ejecutivo, que inicialmente había favorecido la negociación con CC.OO. para debilitar no tanto a la UGT como al PSOE, decidió apoyar la colaboración -a petición, al parecer, de los empresarios- para atemperar y racionalizar la conflictividad. Una estrategia que no impidió su apuesta por USO con la finalidad de afianzarla como tercera fuerza sindical y, por qué no, disponer de una plataforma sindical propia. Sus esfuerzos, sin embargo, resultaron fallidos. La organización no logró en las elecciones sindicales celebradas en 1980 el 10\% de delegados, fijado por el Estatuto de los Trabajadores (ET) para acceder a la condición de organización más representativa, y su fracaso contribuyó a consolidar la «estructura bipolar atenuada», característica del sindicalismo español desde la Transición democrática ${ }^{31}$.

El acercamiento entre la CEOE y el sindicato socialista cuajó en julio de 1979 en la firma del Acuerdo Básico Interconfederal (ABI), el Acuerdo Marco

29 La CEOE comunicó a sus organizaciones asociadas las directrices para la negociación de los nuevos convenios que fijaban un tope para los incrementos salariales del $10 \%$. Los sindicatos acordaron conjuntamente las bases que incluían, entre otras mejoras, aumentos del 16\%. El resultado fueron 1.789 paros y 171.067 .049 millones de horas de trabajo perdidas por los 10.068.000 huelguistas.

30 «El PSOE no estaba muy conforme con nuestros acuerdos con la CEOE porque le parecía que facilitábamos la labor del Gobierno (...). Abril, en cambio, los entendía y los apoyaba, por lo que significaban de diálogo y entendimiento entre los agentes sociales». Conversaciones de N. Redondo con el autor, Lamelas, Antonio, La transición en Abril, p. 179.

31 Soto Carmona, Álvaro, «Conflictividad social y transición sindical», en Tusell, Javier y Sото, Álvaro (eds.), Historia de la Transición, 1975-1986, Madrid, Alianza, 1996, pp. 363408. 
Interconfederal para la negociación colectiva (AMI), en enero del año siguiente y el ET, dos meses después. Algunos especialistas subrayan que tales acuerdos no pueden ser calificados propiamente como pactos sociales, pese a que contribuyeran al desarrollo de la concertación. Sostienen que, en realidad, el ABI fue una declaración de intenciones en la que los firmantes se manifestaban partidarios de negociaciones que implicasen únicamente el diseño del nuevo marco de relaciones laborales. Dicho de otro modo, el desarrollo de los supuestos contenidos en el texto constitucional y, sobre todo, en el ET, por aquel entonces en fase de negociación. Comportaba, además, un reconocimiento mutuo de la autonomía colectiva y de la legitimidad representativa de los actores sociales y, en este sentido, supuso un salto cualitativo en la reducción del acusado intervencionismo estata ${ }^{32}$. La posterior firma del AMI puede considerarse como la consecuencia lógica del primero, pero en su gestación operaron factores políticos que le otorgaron un carácter y un alcance mayores. Movidos por el mismo afán de consolidar un sistema bipartidista, UCD y PSOE acordaron consensuar las líneas directrices del ET y asegurar su viabilidad mediante un pacto que, entre otros objetivos, canalizase la negociación colectiva para el bienio 1980-1981. De ese consenso participaron la UGT y la CEOE, que negociaban con el Gobierno desde hacía meses la redacción del Estatuto, pero no Comisiones Obreras. Su pretensión de un amplio consenso para elaborar lo que -a su juicio- debería ser la constitución del mundo del trabajo, colisionaba con la concepción de sus partners, para los que el texto tenía unos objetivos limitados, ceñidos a la configuración de un nuevo marco de relaciones laborales sustentado en el principio de la negociación ${ }^{33}$. El AMI señaló el comienzo de una nueva etapa en el desarrollo de las relaciones laborales al consagrar una nueva ordenación de la negociación colectiva y un cierto reconocimiento de los derechos sindicales. ${ }^{34}$ Desde esta perspectiva, sentó las bases para la homologación con los países industrializados con economía de mercado y la adecuación de la política económica al paradigma vigente, basado en el abaratamiento del coste de la mano de obra y en la flexibilización del mer-

32 Moreno VIDa, María Nieves, «La naturaleza jurídica de los pactos sociales», en OJEDA AvILÉs, Antonio, La concertación social tras la crisis, p. 76; Miguélez, Faustino, «Sindicalismo y conflictividad social en la España de la transición», Mientras Tanto, Madrid, 24, (1985), pp. 19-44.

33 Soto Carmona, Álvaro, «Comisiones Obreras en la transición y la consolidación de la democracia. De la Asamblea de Barcelona a la Huelga General del 14-D (1977-1988)», en Ruız, David, Historia de las Comisiones Obreras (1958-1988), Madrid, Siglo XXI, 1993, pp. 465 y ss. SerRano del Rosal, Rafael, Transformación y cambio del sindicalismo español contemporáneo, Córdoba, CSIC, 2000, p. 103.

34 Cfr. Marín ArCe, José María, Los sindicatos y la reconversión industrial durante la transición, 1976-1982, Madrid, CES, 1997. 
cado laboral como respuestas idóneas a la crisis.

Paralelamente, la CEOE puso en marcha una estrategia ideada para reducir el peso de CC.OO. y evitar el riesgo de que en España se estableciera una «situación a la portuguesa» ${ }^{35}$. Sus dirigentes apoyaron el cambio de estrategia de la UGT ante la conveniencia de asegurar la fragmentación del mapa sindical y la convicción de que, en caso contrario, el sindicato se hundiría sin remedio. Esa colaboración se amplió y profundizó con ocasión de las elecciones sindicales de 1980, en las que la organización empresarial prestó apoyo técnico y financiero a la UGT. Avalada por la firma del acuerdo y la moderación del PSOE, la llamada «Operación Otoño» se basó en la generalización de las elecciones a las pequeñas y medianas empresas, precisamente aquellas donde CC.OO. tenía una menor o nula implantación, y obtuvo resultados más que satisfactorios al reducir sensiblemente la distancia entre los sindicatos mayoritarios ${ }^{36}$.

Un acuerdo entre las formaciones políticas y pactos parciales entre los agentes sociales apoyados por el Gobierno se habían sucedido hasta este momento, pero en realidad el que ha sido considerado como primer y auténtico pacto social de la democracia no se produjo hasta 1981. El Acuerdo Nacional de Empleo (ANE), firmado apenas tres meses después del 23-F, es inseparable del riesgo de involución política y de la creciente debilidad del Gobierno y del partido que lo sustentaba. Precisamente la acuciante necesidad del ejecutivo de firmar un pacto que fortaleciera su posición indujo una serie de cesiones a las centrales sindicales, que la CEOE aceptó sólo por la presión política del momento ${ }^{37}$, de manera que el resultado fue un compromiso desequilibrado y, en consecuencia, sobre bases débiles e incompletas.

Los mayores réditos del ANE recayeron en CC.OO. El sindicato consiguió reactivar la unidad con UGT, saliendo del peligroso aislamiento en que se hallaba

35 Monteira, Félix, «La huelga general», en Juliá, Santos, Pradera, Javier y Prieto, Joaquín, Memorias de la Transición, Madrid, Taurus, 1996, p. 626.

36 La diferencia entre ambos sindicatos se redujo al 1,6\% en la atribución de representantes en las empresas. Prieto, Carlos, «Los sindicatos», en Del Campo, Salustiano, Tendencias sociales en España, Fundación BBV, tomo II, 1993. GonzÁlez Fernández, A., «La estrategia del pacto social. La CEOE ante la transición española a la democracia», en QuirosACheyrouze, Rafael (ed.), La sociedad Española en la transición. Los movimientos sociales en el proceso democratizador, Madrid, Biblioteca Nueva, pp. 193 - 204.

37 Díaz-Varela, Mar y Guindal, Mariano, A la sombra del poder, Barcelona, Tibidabo Ediciones, 1980, pp. 206-212. El acuerdo contemplaba, entre otros puntos, la renuncia sindical a aumentos salariales superiores al $11 \%$ a cambio de compromisos dirigidos al fomento del empleo, aumento de las pensiones y subsidios, así como mayores coberturas para los parados. Fijaba, además, la presencia de representantes de los agentes sociales en los consejos de determinados organismos de la Administración, consolidando su influencia en el desarrollo y aplicación de las políticas sociales y económicas. 
desde 1978, pudo denunciar los anteriores pactos bilaterales y, al mismo tiempo, mantener su pretensión de un acuerdo global que comprometiera al Gobierno. Sin embargo, los problemas para la aplicación del ANE surgieron de forma casi inmediata. De un lado, porque su efectividad estaba supeditada a la bondad de la política económica del Gobierno, que en poco tiempo se mostró incapaz ante la intensidad de la crisis y los graves problemas internos de $\mathrm{UCD}^{38}$. De otro, por el obstruccionismo de la CEOE ante las limitaciones fijadas a la contratación temporal y el compromiso, realizado a sus espaldas por el Gobierno, de otorgar ayudas institucionales a las centrales como anticipo de la devolución del patrimonio sindical ${ }^{39}$. La estrategia empresarial se completó en el mes de setiembre con su retirada de la comisión de seguimiento del acuerdo, alegando el incumplimiento gubernamental de los compromisos contraídos en materia de presión fiscal, déficit público y por la concesión de subvenciones -denunciadas como financiación directa- a los sindicatos ${ }^{40}$.

La inobservancia del ANE afectó igualmente a los sindicatos y acentuó el descontento hacia las políticas gubernamentales. Las protestas por el «incumplimiento de determinados compromisos de reestructuración, la falta de una política industrial, el electoralismo y la ineficacia de la política económica» se conjugaron con las denuncias sobre la subordinación del ejecutivo a las exigencias de la gran patronal ${ }^{41}$. En suma, la aplicación el acuerdo, en el que tantas esperanzas había puesto el ejecutivo, se convirtió a lo largo de los meses siguientes en un verdadero suplicio que contribuyó a su desgaste político.

\section{LA MUDANZA EN LA RELACIÓN COSTES/BENEFICIOS Y LA CRISIS DE LA CONCERTACIÓN}

La llegada del PSOE al poder en octubre de 1982 introdujo cambios importantes en la política de concertación. Motivaciones de carácter económico y geopolítico confluyeron con la alteración paulatina pero firme de los intereses de cada uno de los actores, es decir, de la modificación en la relación costes-beneficios resultante de los acuerdos. El Gobierno fue el primero en reconsiderar su posición

38 Landa, Juan Pablo, Sindicalismo y Crisis, San Sebastián, Universidad del País Vasco, 1983, p. 174. HopkIn, Jonathan y GUnTHER, Richard, «Una crisis de institucionalización: el colapso de UCD en España», en VV. AA., Partidos políticos: viejos conceptos y nuevos retos, Madrid, Trotta, 2007, pp. 165-208.

39 González Fernández, Ángeles, «La acción sindical de CC.OO. de Andalucía, 19772000», en VV. AA., La conquista de la libertad. Historia de las Comisiones Obreras de Andalucía, 1962-2000, Puerto Real, Fundación de Estudios Sindicales, 2003, p. 723.

40 Calvo Sotelo, Leopoldo, Memoria viva de la transición, Barcelona, Plaza y JanésCambio 16, 1990, p. 163.

41 AHCCOOA, Manifiesto Conjunto de UGT- CC.OO., 1982.

Pasado y Memoria. Revista de Historia Contemporánea, 9, 2010, pp 101-128 
hacia la política de pactos conforme a los requerimientos de la coyuntura abierta en los primeros años 80. La negativa experiencia cosechada por las políticas expansivas de los gobiernos socialistas francés y griego, de un lado, y el grave deterioro de la situación económica, de otro, aconsejaron la aplicación de duras medidas de ajuste para las que, ahora, con una cómoda mayoría parlamentaria, el ejecutivo no precisaba del acuerdo con los agentes sociales ${ }^{42}$. La mudanza del ejecutivo se tradujo en una orientación un tanto ambigua y contradictoria durante la primera legislatura. La aprobación unilateral de la política económica y sociolaboral coexistió con una política de pactos que obtuvo la anuencia de los agentes sociales, que se limitaron a operar a remolque de sus directrices. La cooperación ugetista con el PSOE respondió a consideraciones ideológicas, pero junto a ellas operó también la convicción de que el coste social derivado de su aceptación de las políticas de ajuste quedaría compensado por su fortalecimiento institucional. Muy otra fue la postura de CC.OO., que asumió una estrategia radical y proclive a la maximización del conflicto con el objetivo, precisamente, de acoger en su seno la probable pérdida de poder sindical ugetista ${ }^{43}$.

El primero de los pactos, el Acuerdo Interconfederal (AI), refrendado en 1983 sólo por los agentes sociales pese a las presiones de CC.OO. y de CEOE/ CEPYME para que el ejecutivo se implicase directamente, recogía muchos de los aspectos ya contemplados en acuerdos anteriores. Una continuidad que el Gobierno rompió ese mismo año al aprobar una serie de medidas, no pactadas previamente con los sindicatos, que facilitaban el abaratamiento de los despidos, la desregulación del mercado laboral, la flexibilización de las plantillas y, sobre todo, el inicio de la traumática reconversión industrial. Disposiciones que provocaron frustración y desengaño en los sindicatos, aunque sólo Comisiones Obreras optase por la ruptura y el inicio de una campaña de movilizaciones de protesta.

Paradójicamente, el más amplio de los pactos sociales de la Transición sería también el último. El Acuerdo Económico y Social (AES) fue rubricado en octubre de 1984 por el Gobierno, las organizaciones empresariales y una UGT obligada por las presiones del PSOE. Comisiones Obreras, que estimó el texto

42 SEguRA, Julio, «Del primer gobierno socialista a la integración en la CEE», en GarCía Delgado, José Luis (dir.), Economía española de la transición y la democracia, p. 59-73; Maravall, José María, Los resultados de la democracia: un estudio del sur y del este de Europa, Madrid, Alianza, 1995. Merkel, Wolfgang, ¿Final de la socialdemocracia? Recursos de poder y política de gobierno de los partidos socialdemócratas en Europa occidental, Valencia, Edicions Alfons el Magnànim, 1995.

43 Oliet PalÁ, Alberto, «La concertación social en el período socialista: la crisis de un modelo de intercambio», Política y sociedad, 37 (2001), pp. 131-133. 
insatisfactorio y, sobre todo, como la expresión más acabada de la estrategia para su marginación, acabó autoexcluyéndose ${ }^{44}$. El acuerdo, que permitió la generalización de la contratación temporal y situó la conflictividad en sus niveles más bajos desde los inicios de la Transición, impactó positivamente sobre el conjunto de la economía pero tuvo un elevado coste social. A partir de ese momento las relaciones entre los agentes sociales -especialmente los sindicatos- y el Gobierno se tensaron de manera paulatina hasta desembocar en una clara ruptura que liquidó la concertación. Una secuencia fruto de la interacción de factores diversos. Unos, relacionados con el avance del proceso de integración europeo, el aumento de la competitividad de las empresas en un contexto globalizado y la llamada crisis «fiscal» del Estado del bienestar. Otros, vinculados a los cambios en la percepción de los problemas y de las prioridades de los actores sociales y políticos ${ }^{45}$.

La tensión entre los firmantes del AES tuvo un trasfondo político innegable ante la proximidad de las elecciones legislativas, previstas para 1986. El buen entendimiento que hasta entonces había presidido las relaciones entre el Gobierno y la CEOE dio paso a una aguda crispación, fruto de la combinación de una renovada desconfianza mutua y de cálculos políticos. El malestar del mundo empresarial ante la forma en que se había negociado la adhesión de España a la CEE y el incumplimiento gubernamental de determinados puntos del AES, especialmente el relativo a la adaptación de la legislación laboral a la europea en materia de despido colectivo, favoreció la posición de los sectores críticos con los dirigentes de la patronal. Partidarios de una mayor firmeza ante el ejecutivo, denunciaron internamente la firma del acuerdo como la concesión de un aval a la política económica y diseñaron una estrategia para provocar un relevo en el Gobierno o, cuando menos, acabar con la mayoría absoluta socialista, la llamada «operación Roca» ${ }^{46}$. Para el Gobierno, por otro lado, la aprobación de la Ley

44 El 3 de octubre Nicolás Redondo envió una carta a Felipe González, que nunca se hizo pública, en la que anunciaba su decisión de no asistir a las reuniones de las ejecutivas del partido "porque la UGT esta siendo injustamente tratada por este gobierno socialista», Caro Cancela, Diego, Unión General de Trabajadores-Andalucía. 20 años de sindicalismo, UGT-A, 2000, p. 96. «Nos encontramos con una estrategia de la patronal y sectores del gobierno de presentar una imagen de Comisiones Obreras "irresponsable", de que nos negamos a negociar, estrategia que pretende eliminarnos tanto de la concertación macroeconómica e industrial como de las mesas de los convenios», AHCCOOA, Negociación Colectiva 1984.

45 Monereo Pérez, José Luis, Concertación y diálogo social, p. 66. La evolución económica tras la integración, en ViñALS, José (ed.), La economía española ante el Mercado único europeo: las claves del proceso de integración, Madrid, Alianza, 1992.

46 Iglesias, Rodrigo, «La concertación social desde la perspectiva de las organizaciones empresariales», en ZARAGOZA, Ángel (comp.), Pactos sociales, sindicatos y patronal en España, Madrid, Siglo XXI, 1988, p. 162. El País, 10-8 y 19-9-1985. El intercambio de acusacio- 
sobre la Reforma del Plan de Pensiones tuvo un coste innegable y, sobre todo, provocó la primera exteriorización pública del malestar del sindicato socialista ante su política socioeconómica. En consecuencia, resulta plausible que tensara el conflicto dialéctico con la patronal para demostrar su firmeza ante los sindicatos y la opinión pública. La CEOE aprovechó la ocasión para retirarse, aunque temporalmente, de la comisión de seguimiento del AES, en una actitud que reflejaba su desinterés hacia la política de pactos sociales ante la parcial aplicación de políticas neoliberales y la debilidad de los sindicatos ${ }^{47}$.

El enfrentamiento en el seno de la familia socialista se enconó a partir del triunfo electoral del PSOE. Su segunda mayoría absoluta reforzó en sus dirigentes la convicción de que su política económica era la que más convenía al país para garantizar la modernización y, en consonancia con ello, mostraron un nulo interés por el consenso. La frustración de las expectativas de la UGT sobre su participación en la elaboración de las políticas públicas y el creciente malestar ante la gestión gubernamental ya se había exteriorizado públicamente pero hasta entonces de manera prudente ${ }^{48}$. El precipitante para la ruptura se produjo a finales de 1986 cuando la victoria de CC.OO. en las grandes empresas y en los sectores clave empañó el triunfo global ugetista en las elecciones sindicales. El avance del sindicato rival vino a confirmar la idea de que había pagado una elevada factura por su lealtad al Gobierno y de la necesidad de una nueva estrategia frente a los poderes públicos y la patronal. Un cambio que se materializó poco después en la reactivación de la unidad de acción sindical, facilitada por la renovación en el liderazgo de CC.OO., y la escenificación de la ruptura mediante la convocatoria de huelga general el 14 de diciembre de $1988^{49}$.

nes en el segundo semestre del año puede seguirse a través de este diario.

47 Boletín del Circulo de Empresarios, 37 (1987) citado en Martínez Alier, J. y Roca Husmet, Jordi, «Economía política del corporativismo en el Estado español: del franquismo al posfranquismo», REIS, Revista Española de Investigaciones Sociológicas, no 41 1988, p. 49.

48 A lo largo de 1985 el sindicato denunció el incumplimiento de ciertos puntos del AES por parte del Gobierno y N. Redondo votó en contra de la Ley sobre la Reforma de las Pensiones, pero el sindicato no secundó la huelga general de protesta convocada en junio de 1985 por CC.OO.

49 La decepción de UGT por los resultados electorales, a pesar de obtener casi el 41\% de los delegados frente al 34,5\% obtenido por CC.OO., en EsPinA, Álvaro, «El "guadiana" de la concertación neocorporatista en España. De la huelga general de 1988 a los acuerdos de 1997», en Miguélez, Faustino y PRieto, Carlos, Las relaciones de empleo en España, Madrid, Siglo XXI, 1999, p. 378. Cfr. Juliá, Santos, La desavenencia: partido, sindicatos y huelga general; García Santesmases, Antonio, Historia, memoria y futuro: Nicolás Redondo (1927-2007), Madrid, Fundación Largo Caballero, 2007. Sobre la posición de CC.OO., GutiérRez, Antonio, "Concertación social y coyuntura política en España», en ZaragozA, Angel (comp.), Pactos sociales, sindicatos y patronal en España, pp. 120-143. 
Al margen de sus causas inmediatas, como el proyecto del Plan de Empleo Juvenil, el conflicto entre los sindicatos y el Gobierno obedeció a razones de mayor envergadura. En realidad, debe entenderse como la respuesta de los sindicatos a la experiencia de la concertación que -a su juicio- los había reducido a la condición de avalistas y legitimadores de las decisiones adoptadas por los gestores gubernamentales. Esa negativa percepción de la concertación, de la inversión en la relación coste-beneficios para sus organizaciones, fue interiorizado por las centrales sindicales a mediados de los años 80 . No fue una casualidad. Por aquel entonces -y este fenómeno ya se había planteado a comienzos de la década en la Europa occidental- los sindicatos se encontraron inmersos en una acusada crisis de representatividad. Como es obvio, no tuvo su origen en las legislaturas socialistas, aunque se aceleró y profundizó en esos años por la unilateralidad de su política económica y, sobre todo, por el hecho de que fuera aplicada por un Gobierno de izquierdas ${ }^{50}$.

La centralización del marco negociador implicó la pérdida de autonomía de la empresa, de forma que los delegados sindicales se vieron reducidos a operar como el último escalón en la aplicación de las directrices fijadas de manera global $^{51}$. La consiguiente pérdida de la iniciativa en los niveles inferiores, precisamente aquellos donde existía un contacto directo e inmediato con los trabajadores, llevó aparejado su alejamiento del proceso de toma de decisiones que fue acompañado, inevitablemente, de una creciente desafección. Dicho de otra manera, el control centralizado sobre los diversos grupos de trabajadores generó la incapacidad de los sindicatos para representar todos los intereses y la aparición de identidades nuevas que ya no se sentían vinculadas al sindicato tradicional ${ }^{52}$. Se imponía, por tanto, adoptar un nuevo modelo sindical y nuevas estrategias de acción que permitieran abordar con éxito la progresiva fragmentación del mercado laboral en el seno de una economía cada más internacionalizada y competitiva ${ }^{53}$.

50 SerRano del Rosal, Rafael, Transformación y cambio del sindicalismo español contemporáneo, Córdoba, CSIC, 2000, pp.129-148.

51 Baylos, Antonio, «La concertation en Espagne: étapes et modèles», en VV. AA., L'Emploi en Espagne, Marchés du travail et relations profesionnelles, Paris, Syros/Alternatives, 1991 pp. 159-166.

52 Garofalo, Mario G., «Naturaleza de la concertación social», en Ojeda Avilés, Antonio, La concertación tras la crisis, p. 63; REGINI, Marino, «El declinar del intercambio político centralizado y la emergencia de nuevas formas de concertación», op. cit., pp. 17-19; Monereo, José Luis, Concertación y diálogo social, p. 49.

53 Montes Muñoz, Jaime, «Los acuerdos generales 1977-1988», en Ojeda Avilés, Antonio, La concertación social tras la crisis, pp. 209-212. JordANA, Jacinto, «Sindicatos y política en España: la influencia de las condiciones organizativas en las estrategias sindicales», 


\section{LA RUPTURA DEL JUEGO: LOS SINDICATOS COMO ACTORES POLÍTICOS}

En su búsqueda de la representatividad perdida, a partir de 1987 los sindicatos rechazaron los acuerdos globales que comportasen un marco centralizado de negociación para, en su lugar, plantear una modalidad diferente. Tal como formularon en su propuesta conjunta, apostaban por la firma de pactos con un carácter pluridireccional, flexible y descentralizado para, entre otros objetivos, lograr la inclusión de los colectivos que hasta entonces habían permanecido ajenos a la política de pactos (funcionarios, parados y pensionistas). Una propuesta -la de los acuerdos descentralizados- que contaba con el beneplácito de la CEOE al estimar que los incrementos salariales debían conceptuarse como una variable interna de la empresa ${ }^{54}$.

La alternativa sindical a la concertación tripartita implicaba el abandono del modelo sindical pactista y el despliegue de la fórmula de confrontación con la finalidad de impulsar lo que vino en denominarse «el giro social ${ }^{55}$. En consonancia con ese objetivo, la nueva estrategia tuvo una clara dimensión política. Respaldados por el éxito de la huelga general del 14-D, los sindicatos se atribuyeron la condición de actores políticos y, como tales, dotados de legitimidad para exigir la satisfacción de las demandas sociales hasta entonces insatisfechas por los poderes públicos. Dicho de otro modo, su indudable capacidad de movilización les llevó a estimar que contaban con el apoyo y la fuerza suficientes para imponer sus planteamientos a los empresarios y, sobre todo, dictar al ejecutivo la política socioeconómica. Conforme a esos planteamientos, a comienzos de 1989 los sindicatos aplicaron su nueva estrategia orientada a la firma de pactos bilaterales con la argumentación de que las cuestiones a negociar no requerían la participación de la patronal ${ }^{56}$.

Para su desencanto, el ejecutivo -aunque sorprendido y debilitado por el impacto de la huelga- no atendió la demanda de giro social tal como esperaban ${ }^{57}$.

REIS, Revista Española de Investigaciones Sociológicas, 8-9 (1994) pp. 160-161.

54 Martínez Alier, Joan y Roca Husmet, Jordi, «Economía política del corporativismo en el Estado español: del franquismo al posfranquismo», p. 49.

55 La búsqueda de la representación en Monereo, José Luis, Concertación y diálogo social, p. 67. Jordana, Jacint, «Sindicatos y política en España», p. 180. GonzÁlez Fernández, Ángeles, «La acción sindical de CC.OO. de Andalucía, 1977-2000», en VV. AA., La conquista de la libertad, pp. 748-750 y 756-757.

56 Medidas como el desempleo, reforma de la seguridad social y negociación colectiva de los funcionarios. OJEDA AvilÉs, Antonio, «El bilateralismo como respuesta (impropia) a la crisis de la concertación», en OJedA Avilés, Antonio (dir.), La concertación social tras la crisis, pp. 175-176.

57 Con todo, los sindicatos obtuvieron medidas redistributivas en materia de sanidad, pensiones, protección del desempleo, entre otras. Powell, Charles, España en democracia, 
En ello pesaron consideraciones de naturaleza diversa. La necesidad de un crecimiento económico estable y sano en el marco de la CEE fue una de ellas, pero en la resolución del ejecutivo influyeron sobremanera tres argumentos relevantes: el notorio desajuste entre la afiliación a los sindicatos y su capacidad de movilización; la constatación de que los asalariados, pese al masivo seguimiento del paro, eran partidarios de la firma de nuevos acuerdos laborales y, por último, sus estimaciones sobre el atractivo que sus políticas de saneamiento ejercía sobre el electorado de centro ${ }^{58}$. El fracaso de las negociaciones y la consiguiente ruptura con el Gobierno supuso la escenificación del hundimiento de la concertación, pero no de la voluntad sindical de operar como actores políticos. Conforme a ese papel, en vísperas de las elecciones legislativas de 1989 presentaron ante la opinión pública lo que podría entenderse como su propio programa de política económica, centrado en el aumento del gasto público para fomentar el empleo, mejorar la protección social, redistribuir la renta y garantizar el derecho a la participación de los trabajadores en la empresa ${ }^{59}$. La propuesta obtuvo un mayor respaldo social y forzó al Gobierno a firmar una serie de acuerdos en enero del año siguiente, en los que se incluían el reconocimiento del derecho de información de los representantes de los trabajadores en los centros de trabajo. Por su parte, la cúpula empresarial, que había asistido impotente y alarmada al desafío sindical y a una posible cesión del Gobierno que, a su juicio, repercutiría negativamente sobre el normal funcionamiento de la democracia, convirtió el llamado control sindical de la contratación en ariete contra los acuerdos. Firmados sin su concurso y, por ello mismo -estimaba- de dudosa legitimidad, la CEOE llegó a solicitar la mediación de la OIT y la Organización Internacional de Empleadores (OIE) para evitar la ruptura del tripartismo ${ }^{60}$.

1075-2000, Barcelona, Plaza y Janés, 2001, pp. 436 y ss.

58 «(González) explicó la semana pasada por qué creía que había tenido que dar la espalda a sus antiguos compañeros del movimiento sindical. (...) Los sindicatos le habían pedido que realizara una política incompatible con la buena marcha de la economía española», Herald Tribune, 20-2-1989. Sobre los indicadores de representatividad sindical (tasas de afiliación y elecciones sindicales) y la paradoja que caracteriza el sindicalismo español (baja afiliación y alta participación electoral, acompañada de una elevada capacidad de movilización) véase Prieto, Carlos, «Los sindicatos», en Del Campo, Salustiano, Tendencias sociales en España, Madrid, Fundación BBV, tomo II, pp. 225-244; Sobre la baja densidad de la afiliación, Rodríguez, C., «Determinantes de la afiliación sindical», Moneda y crédito, 203 (1996), pp. 149 y ss. Los cálculos electorales en Oliet Palá, Alberto, «La concertación social en el período socialista: la crisis de un modelo de intercambio», p. 136.

59 El País, 5 y 24-10-1989. Véase Caro Cancela, Diego, 20 años de sindicalismo, p. 128.

60 Sobre el contenido de los acuerdos, Solans Latre, Miguel Ángel, Concertación social y otras formas de neocorporativismo en España y en la comunidad europea, Madrid, Tecnos, 
Acuciado por el reto de la unión económica y monetaria y la perentoriedad de afrontar los graves desequilibrios que amenazaban la incorporación española ${ }^{61}$, esa misma primavera el Gobierno ofreció a partidos políticos y agentes sociales la negociación de un plan de ajuste para reducir la inflación y el déficit públicos. El llamado Plan de Competitividad o Pacto Social de Progreso, encontró una favorable acogida en la CEOE, que asumió el plan como propio, y en las formaciones parlamentarias minoritarias. No así en el PP, ya bajo el liderazgo de José María Aznar, y en los sindicatos. No cabe duda que los nuevos sacrificios salariales que comportaba los ubicaba en una difícil posición que justificaba su negativa, pero pueden argüirse otras razones de no menor peso. Entre ellas, que su aceptación supondría directamente la quiebra del modelo de pactos por el que habían batallado desde 1987, unos acuerdos descentralizados, para regular aspectos específicos y, sobre todo, bilaterales y negociados con discreción ${ }^{62}$. La imposibilidad de reeditar los Pactos de la Moncloa no arredró al Gobierno que anunció su voluntad de aplicar las medidas de ajuste aún sin el concurso de las fuerzas políticas y agentes sociales. Como prueba de su firmeza en la primavera de 1992 lanzó su Plan de Convergencia en el que se incluyó el que fue rápidamente conocido como el «decretazo». El aumento del tipo de cotización para recibir prestación de desempleo y la reducción de su importe fue considerado como «la ruptura del consenso y un claro rasgo de autoritarismo» ${ }^{63}$ por los sindicatos, que se aprestaron a convocar una nueva huelga general para el 28 de mayo.

La situación, sin embargo, era muy distinta a la de cuatro años atrás. El evidente enfriamiento de la economía y la habitual prudencia de los asalariados en tiempo de crisis contribuyen a explicar el menguado seguimiento del paro. El relativo fracaso de la huelga, un conflicto light que logró paralizar la actividad productiva pero no la vida ciudadana ${ }^{64}$, no resolvió el problema de fondo: el

1995, pp. 150-154. «Si esta actitud de imponer cambios en la política económica del Gobierno por parte de los sindicatos se consolida, estamos ante una nueva formulación del sistema democrático», Declaraciones de J. M. Cuevas, El País, 13-1-1989. La solicitud a la OIT, en ibidem, 19-6-1990.

61 Viñals, José, «La economía española ante el cambio de siglo», en Tusell, Javier, Lamo DE Espinosa, Emilio y PARDo, Rafael (eds.), Entre dos siglos, pp. 420-434.

62 El País, 29-3-1990. La aceptación de la CEOE y la negativa de los sindicatos que, en respuesta, presentaron una alternativa propia -la Iniciativa Sindical de Progreso- en ibidem, 20-4 y 28-7-1991. Cfr. Solans Latre, Miguel Ángel, Concertación social, pp. 162-172. La postura sindical en OliET PALÁ, Alberto, «La concertación social en el período socialista: la crisis de un modelo de intercambio», p. 140.

63 El País, 5-4-1992.

64 SuÁrez, Miguel y CASAdo, Demetrio, V Informe sociológico sobre la situación social en España, Fundación Foessa, p. 591. Fernández Durán, Ramón, La explosión del desorden. La 
grave deterioro de la economía que, iniciado en 1992, mudó en recesión el año siguiente. La pérdida de competitividad, el notable aumento de los salarios reales -no sujetos a contención pactada desde 1987 y superior al del resto de los socios comunitarios- el desequilibrio de la balanza de pagos y una inflación persistente coexistían con una fuerte caída de la demanda y unas elevadas tasas de desempleo, en cotas cercanas al 23\% a comienzos de 1993. Fue entonces cuando, de nuevo y al igual que sucediera en la Transición democrática, la política de concertación surgió como el medio idóneo para repartir los costes del ajuste.

Su conveniencia, evidente para todos, tropezó con la distancia abisal que separaba las posiciones de las partes. Los sindicatos, acorde con su papel como actores políticos, opusieron argumentos de similar naturaleza. Dicho con claridad, el problema radicaba en la política económica del Gobierno, sencillamente «incompatible» con la propuesta de un acuerdo social, que sólo sería factible tras su modificación. La CEOE se mostró favorable, siempre y cuando el acuerdo estuviera encaminado a introducir una mayor flexibilidad en la contratación y en el despido. Una posición compartida en no poca medida por el ejecutivo, para el que la salida de la crisis requería, entre otras exigencias, reducir la rigidez normativa que adolecía el mercado de trabajo para fomentar la competitividad.

Las negociaciones a tres bandas se hallaron en punto muerto pocas semanas después, sin que el ultimátum del Gobierno a los agentes sociales surtiera efecto alguno. El ejecutivo entonces decidió aprobar unilateralmente una reforma del mercado laboral que introdujo medidas flexibilizadoras en línea con las solicitadas desde la CEOE, hasta el punto que algunos autores subrayan la presencia de una concertación implícita entre ambos ${ }^{65}$. En este sentido, el fracaso de las negociaciones no puede achacarse sin más a la irreductibilidad de los sindicatos. Buena parte de la responsabilidad recayó en el Gobierno. Carente de mayoría parlamentaria y sacudido el partido que lo sustentaba por el radical antagonismo entre renovadores y guerristas, priorizó la búsqueda de aliados políticos -las formaciones nacionalistas, en especial CIU- en menoscabo de los acuerdos sociales,

metrópoli como espacio de la crisis global, Madrid, Ed. Fundamentos, 1993, p. 312; Oliet PALÁ, Alberto, «La concertación social en el período socialista: la crisis de un modelo de intercambio», pp. 141-142.

65 La posición de los agentes sociales en El País, 17-1, 25-3 y 3-6-1993. Entre otras, incluía el despido por causas objetivas con indemnización de 20 días, la posibilidad de contratación a tiempo parcial y el contrato de aprendizaje. Sobre su contenido, que afectó prácticamente a toda la legislación laboral en vigor hasta la fecha, véase VV. AA., La reforma laboral de 1994, Cuenca, Universidad de Castilla-La Mancha, 1996. Monereo, José Luis, Concertación y diálogo social, p. 71. La CEOE denunció la reforma por «tímida, corta e insuficiente», El País, 17-11-1993; los sindicatos, como «la mayor agresión contra los trabajadores desde que se inició la transición democrática», La Vanguardia, 5-12-1993. 
o por mejor decir, de los acuerdos con unos sindicatos, a los que, además, poco podía ofrecer en materia de condiciones laborales ${ }^{66}$.

Abocados a una nueva huelga general, CC.OO. se lanzó a ella sin reservas frente a las reticencias de UGT. Probablemente atenazada por su precaria situación financiera, agudizada tras el fracaso de la cooperativa de viviendas PSV, y dependiente del apoyo financiero del Gobierno, adoptó un "pragmatismo de supervivencia» ${ }^{67}$. Esto es, frente a la pretensión de CC.OO. de organizar la huelga antes de finales de año, consiguió posponerla hasta los últimos días de enero para no romper del todo los puentes con los gestores gubernamentales. Su maniobra facilitó que el ejecutivo pudiera aprobar, con el apoyo de CiU, los presupuestos generales al tiempo que la dilación del paro amortiguaba un tanto el malestar social. Junto a las dificultades financieras, compartidas -aunque en menor medida- por Comisiones Obreras, no pueden descartarse otras consideraciones que convirtieron la huelga general en una puesta en escena más que en una demostración de oposición frontal, pese a que la convocatoria resultó un éxito incuestionable. La idea de que la caída del Gobierno socialista podría facilitar el triunfo electoral del PP y, en consonancia, la aplicación de una mayor dureza en la reforma de las condiciones laborales, sería una de ellas. Las concesiones realizadas por el ejecutivo en materia de subvenciones, negociación colectiva y elecciones sindicales, que venían a reforzar el bisindicalismo hegemónico, sería la otra. Sin embargo, no ha de olvidarse que a estas alturas el sistema de relaciones laborales gozaba de una autonomía que facilitaba su despliegue al margen del sistema político. En consonancia y sin que ello suponga negar el indudable impacto político del paro, amplios sectores de la población ya no confiaban en la huelga general como instrumento para modificar las políticas públicas. Así, además, había quedado demostrado en 1993, año en que el malestar social hacia el Gobierno no se tradujo en una retirada del apoyo electoral hacia el partido que lo sustentaba ${ }^{68}$.

La estrategia de la confrontación tuvo, además, un coste elevado para los sindicatos mayoritarios a tenor de los resultados de las elecciones sindicales de

66 La actitud de CiU, en La Vanguardia, 14-12-1993. La OIT respaldó la reforma del mercado de trabajo elaborada por el Gobierno, El País, 4-2-1994.

67 Oliet PalÁ, Alberto, «La concertación social en el período socialista: la crisis de un modelo de intercambio», pp. 142-144.

68 El País, 6-12-1993. El paro fue secundado, según los datos del Ministerio de Trabajo, por un $32,3 \%$ de la población activa. Los sindicatos, en cambio, sostuvieron un seguimiento del $90 \%$, pero la huelga no afectó a la vida cotidiana. Espina, Álvaro, «El "Guadiana" de la concertación neocorporatista en España: de la huelga general de 1988 a los acuerdos de 1997», en Miguélez, F. y Prieto, C., Las relaciones de empleo en España, Madrid, Siglo XXI, p. 383. 
1994-1995 en las que, en conjunto, perdieron unos 40.000 delegados en relación a 1990. La ventaja adquirida por CC.OO, que recuperó el liderazgo perdido en 1982, no impidió que, al igual que en UGT, cundiera la alarma ante los avances logrados por candidaturas independientes y de empresa, más apegadas a las realidades específicas de los centros de trabajo. El temor a la posible consolidación de «terceras vías sindicales», junto a otros factores de índole interna, se saldó con la incorporación a sus órganos directivos de líderes sindicales partidarios de abandonar la vía de la confrontación ${ }^{69}$.

La reorientación de la acción sindical en ambas organizaciones, unido a la aparición de un nuevo escenario político tras el triunfo electoral del PP en las legislativas de 1996, facilitó la firma de nuevos acuerdos. Falto de una mayoría parlamentaria suficiente, los imprescindibles acuerdos políticos con partidos nacionalistas tuvieron su correlato en el diálogo con los agentes sociales en una dinámica sustentada en buena medida sobre la renuncia de los sindicatos a su papel como actores políticos, esto es, a su pretensión de influir sobre el marco de relaciones laborales conforme a consideraciones políticas. El nuevo clima se materializó rápidamente en una serie de acuerdos, que se desplegaron en dos ejes complementarios. Los pactos firmados entre los sindicatos y el Gobierno de José María Aznar, como el firmado en 1996 sobre Consolidación y Racionalización del Sistema de Seguridad Social, del que se autoexcluyó la CEOE al estimar que se apoyaba en una concepción sesgada y parcial del llamado «Pacto de Toledo». La segunda vertiente se desenvolvió en torno a los acuerdos sindicatos-organizaciones empresariales sobre aspectos concretos, conocidos como «acuerdos monográficos de concertación». Entre ellos, el Acuerdo de Solución Extrajudicial de Conflictos (1996) o los Acuerdos Interconfederales para la Estabilidad en el Empleo y sobre Negociación Colectiva, ambos firmados en 1997, por los que se abarataba el coste del despido y se racionalizaba la atomizada estructura de la negociación colectiva, respectivamente. La reactivación del diálogo social y su materialización en estos pactos tuvo positivas repercusiones en la medida que facilitaron la introducción, en los convenios colectivos, de algunas de las reformas laborales aprobadas en 1994, inaplicadas en la práctica precisamente por la falta de consenso ${ }^{70}$. Al mismo tiempo, tuvieron una continuación, podríamos decir natural, en el acuerdo sobre Negociación Colectiva (ANC) firmado por la patronal (CEOE y CEPYME) y los sindicatos mayoritarios en 2002 y que sería

69 Ibidem, pp. 386-387.

70 El Mundo, 9-4-1997. Monereo, José Luis, Concertación y diálogo social, p. 72. Pérez InfanTE, José Ignacio, «La concertación y el diálogo social en España, 1977-2007», Revista del Ministerio de Trabajo e Inmigración, 81, p. 62. 
renovado a lo largo de los años siguientes por sus positivas consecuencias para ambas partes.

La luna de miel estaba llamada, sin embargo, a tener una corta vida. Ya a lo largo de 2001 las relaciones entre el Gobierno y los agentes sociales -o por mejor decir los sindicatos -comenzaron a resquebrajarse. Es cierto que Aznar anunció, tras las elecciones legislativas del año anterior, su voluntad de mantener, sin condiciones, el compromiso con el diálogo social, pero su recién estrenada mayoría absoluta trastocaron las directrices que habían regido sus políticas durante la primera legislatura. La quiebra del diálogo social en la primavera de 2002 no puede achacarse únicamente al Gobierno. Para entonces, la UGT ya había dado pruebas evidentes del endurecimiento de su posición, hasta el punto de poner en riesgo la unidad de acción sindical. Su resistencia, a la que vino a añadirse el conflicto que enfrentaba al «sector oficial» con los «críticos» en el seno de CC.OO., dejó además poco espacio de maniobra a José María Fidalgo para mantener en solitario la estrategia de la concertación ${ }^{71}$. La conclusión lógica, la aprobación unilateral por el Gobierno de una nueva reforma del mercado laboral, también conocida como el «decretazo», que abarataba nuevamente el coste del despido, dio lugar a una nueva convocatoria de huelga general, el 20 de junio. Mayor impacto que la jornada de paro tuvo la escalada de tensión puesta en práctica por los sindicatos en el verano-otoño de ese mismo año para que, finalmente -y por primera vez-, el ejecutivo se aviniera a flexibilizar los términos del decreto-ley y a restablecer el diálogo con los sindicatos ${ }^{72}$. Las concesiones realizadas por el Gobierno, sin embargo, no afectaron a dos aspectos, negativos ambos para los intereses de los trabajadores: la desaparición de los salarios de tramitación en caso de despido improcedente y el endurecimiento del concepto de «empleo adecuado» para los perceptores de las prestaciones por desempleo.

La primera legislatura Rodríguez Zapatero (2004-2008) se desarrolló bajo parámetros similares a la inicial de Aznar. El diálogo social operó como uno de los puntales clave de un ejecutivo carente de mayoría absoluta y dependiente del apoyo de formaciones políticas minoritarias. Tal como volvería a plantear

71 El País, 23-3-2000. La dureza de UGT se reflejó en su ausencia del acuerdo sobre pensiones firmado por el Gobierno, la CEOE y CC.OO., El Mundo, 15-3 y 9-4-2001. La crisis de éstas últimas, en La Vanguardia, 18-2-2002. Véase GonzÁlez, Juan Jesús, «Las bases sociales de la política española», REIS, 4 (2204), pp. 130-133.

72 La Vanguardia, 21-6-2002. El anuncio de la escalada sindical, en El Mundo, 30-6-2002. La rectificación del Gobierno, que incluyó el nombramiento de un nuevo ministro de Trabajo, ibidem, 14-12-2002. Cabe subrayar que el Tribunal Constitucional anuló el «decretazo» cinco años después por la urgencia de su aprobación, si bien la sentencia no tuvo efecto práctico alguno porque el Gobierno ya lo había modificado, El País, 303-2007. 
cuatro años más tarde, el presidente del Gobierno enfatizó la necesidad de un gran acuerdo social que garantizara la mejora de la estabilidad en el empleo, el incremento de la productividad y de la competitividad de la economía, todo ello inserto en un modelo de crecimiento equilibrado que permitiera avanzar en la cohesión social y la sostenibilidad ambiental. Conforme a esos supuestos los contactos preliminares dieron lugar a la firma de una declaración de intenciones firmada a tres bandas en la que Rodríguez Zapatero sostuvo que nada se aprobaría sin el consenso previo de los agentes sociales ${ }^{73}$. El discurrir de las negociaciones fue, sin embargo, más lento y problemático de lo previsto por la interacción de distintos factores. El más importante de ellos residió, nuevamente, en las disensiones entre las partes, e incluso en el seno del Gobierno, sobre el alcance y naturaleza de la reforma. La introducción de la cláusula de revisión en el Salario Mínimo Interprofesional (SMI), conforme a la promesa de Zapatero de incrementar su cuantía de manera progresiva a lo largo de la legislatura, contaba con el apoyo de los sindicatos y de Jesús Caldera, ministro de Trabajo y Asuntos Sociales. El rechazo provino, como es lógico, de la CEOE, pero también de Pedro Solbes, ministro de Economía, de Jaime Caruana, gobernador del Banco de España, y del FMI ante los riesgos inflacionistas que comportaba una indización de la política de rentas ${ }^{74}$.

La cláusula de revisión del SMI, y la consiguiente modificación del ET, no constituían, sin embargo, el núcleo duro del pacto. Se trataba, en realidad, de una nueva reforma del mercado laboral basada en la llamada flexiseguridad, el compromiso entre la seguridad en el empleo para el trabajador y la flexibilidad para las empresas. En definitiva, la reforma se sustentaba en el abaratamiento «de los mecanismos de entrada y salida del mercado laboral» como herramienta para fomentar la creación de empleo y limitar la temporalidad en la contratación, considerados como los dos grandes problemas del mercado de trabajo. La dilación de las negociaciones ante la falta de acuerdo entre los agentes sociales llevó al Gobierno -al igual que hiciera el ejecutivo de Aznar en 1997-a presionar con la aprobación de la reforma por decreto-ley. Una forma de coerción que no llegó a hacerse efectiva, entre otras razones por la más que probable oposición de sus aliados políticos, IU y ERC. La firmeza de la patronal y los sindicatos en sus respectivas posturas cedió parcialmente ya entrado 2006 y sólo ante la conveniencia de visualizar un acuerdo que mantuviera viva la concertación, asentara el creci-

73 El Gobierno pretendía, entre otros objetivos, reducir la contratación temporal hasta el 25\%, El País, 9-7-2004; La Vanguardia, 19-7-2004.

74 La Vanguardia, 5 y 12-1-2005. La oposición de la CEOE se sustanció en el bloqueo de las negociaciones para la renovación del AINC, lograda sólo una vez que las partes acordaron aparcar el tema de la cláusula de revisión, ibidem, 5-3-2005. 
miento económico y fomentara la creación de empleo. El resultado, el «Acuerdo para la mejora del crecimiento y el empleo» fue una reforma consensuada, pero inevitablemente limitada e insuficiente. Una ocasión desperdiciada que, si bien garantizaba la paz social, posponía cortar el nudo gordiano, la desequilibrada estructura del mercado laboral entre los trabajadores con contrato indefinido y los temporales, para años venideros. Algunos analistas han apuntado que el escaso impacto de la reforma para reducir las disfunciones en el mercado de trabajo ratificaba el agotamiento del actual marco de relaciones laborales y la necesidad de aplicar medidas estructurales y de carácter integral que deberían incluir, junto a otras cuestiones, la negociación colectiva, las prestaciones por desempleo y las políticas activas de empleo ${ }^{75}$.La práctica concertadora a lo largo de esta legislatura obtuvo, sin embargo, resultados significativos mediante la firma de diversos acuerdos tripartitos y de otros suscritos únicamente por el Gobierno y los sindicatos entre los que cabe destacar los relacionados con la aplicación de la ley de dependencia, el fomento de la igualdad de género y la reforma de la seguridad social, entre otros ${ }^{76}$.

\section{Conclusiones}

Tras la muerte del general Franco y el inicio del proceso de Transición a la democracia, la concertación se desarrolló como correlato necesario, en el ámbito social, al consenso partidario que posibilitó el cambio político. Precisamente por ello, la concertación no ha de entenderse sólo como la respuesta a una situación de crisis económica cuya solución requería la corresponsabilidad de sindicatos y empresarios en la aplicación de un programa de ajuste y estabilización. Más allá de sus objetivos económicos y laborales, la concertación asumió una naturaleza social y política. Contribuyó a reforzar la legitimidad de los nuevos poderes públicos -prestación de singular importancia en los procesos transicionales-, canalizó la participación de los agentes sociales en la elaboración e implementación de las políticas públicas y, desde esa perspectiva, desempeñó un papel determi-

75 VV. AA., Más y mejor empleo en un nuevo escenario socioeconómico: por una flexibilidad y seguridad laborales efectivas. Informe de la Comisión de Expertos para el diálogo social, Madrid, MTSS, 2005. La Vanguardia, 7-5-2005. La postura de la CEOE y de los sindicatos en ibidem, 15-5- 2005. La reforma, que entró en vigor el 1 de julio de 2006, fue complementada con otros acuerdos sobre pensiones y seguridad social. Un balance sobre sus resultados, en Conde-Ruiz, J. Ignacio, Felgueroso, Florentino y García Pérez, José Ignacio, «Las reformas laborales en España: un modelo agotado», Papeles de Economía Española, 124 (2010) (www.fedea.es/pub/est_economicos/).

76 Cfr. Pérez Infante, José Ignacio, «La concertación y el diálogo social en España», pp. 6467. 
nante en la consolidación de la democracia.

La necesidad de medidas estructurales que precisan para su eficacia de un acuerdo Gobierno-agentes sociales y la incorporación de éstos al consenso transicional, no fue el único aliciente para la concertación. Las expectativas de alcanzar en el proceso de diálogo objetivos concretos, definidos en función de intereses propios operaron como formidables incentivos. Conforme a ese planteamiento, la concertación se convirtió en escenario por excelencia del juego de intereses entre los actores intervinientes y, como tal, proceso en el que la confrontación y el consenso siempre han estado presentes, condicionados por factores internos, como la coyuntura política y la situación de cada una de las partes, y externos, derivados de la plena inserción de la economía española en una economía cada vez más interdependiente y globalizada.

Impulsada siempre desde el Gobierno, aunque no siempre en el caso de ejecutivos en minoría, la concertación en España se ha basado, en buena medida aunque no siempre, en una aminoración pactada de los derechos laborales como mecanismo idóneo para fomentar la inversión, asegurar el crecimiento y salvar el empleo. En contrapartida, la política concertadora ha contribuido en gran medida a la permanencia de un modelo de relaciones laborales rígido. La firma de pactos globales y centralizados implicó la pérdida de autonomía de los representantes sindicales en los centros de trabajo y operó negativamente sobre el contenido de la negociación colectiva, reducida poco más que a la aplicación de las directrices elaboradas a nivel nacional, al margen de la realidad cotidiana del trabajo y de los trabajadores.

Desde la perspectiva de los gestores gubernamentales, los acuerdos han operado como un instrumento eficaz para garantizar la gobernabilidad y reforzar su legitimidad a la hora de aplicar políticas económicas impopulares. Para los agentes sociales, los beneficios inherentes a la práctica de la concertación ejercieron un atractivo evidente. Plenamente legitimados por el Gobierno como mediadores sociales, reconocidos como tales interlocutores por sus partners, UGT y CC.OO. -en su condición de sindicatos más representativos- al igual que de la CEOE, disfrutaron de un status público que facilitó, en la delicada coyuntura transicional, el aumento de la afiliación, la construcción de redes organizativas de ámbito nacional y el acceso a los ámbitos de decisión política. Las ventajas reportadas por su institucionalización fueron acompañadas inevitablemente de consecuencias negativas, derivadas de su posición subordinada ante los poderes públicos y la obligada centralización de su funcionamiento interno, pareja a la estructura centralizada de la praxis concertadora. Sus efectos se dejaron sentir con menos intensidad en la CEOE, pese a que han propiciado la creación de diversas organizaciones empresariales independientes y críticas con el liderazgo 
y estrategias de sus dirigentes. Los sindicatos hubieron de pagar un coste muy superior. El centralismo orgánico comportó su incapacidad para adaptarse al desarrollo de una economía cada vez más internacionalizada y competitiva y a un mercado laboral progresivamente fragmentado. La crisis de representatividad consiguiente forzó la adopción de una estrategia de confrontación con el Gobierno y la búsqueda de un nuevo modelo de concertación, descentralizado y flexible. El resultado, la firma de acuerdos bilaterales sobre aspectos concretos -aunque de aplicación general-, se ha desarrollado a lo largo de los últimos años aunque, puntualmente, se han firmado algunos -pocos- acuerdos trilaterales, siempre a instancias del Gobierno y siempre con el objetivo de garantizar la competitividad de la economía española y la preservación del empleo, aun a riesgo de comportar una reducción de los derechos laborales conquistados por los trabajadores. 